\title{
HIV, HCV and SARS-CoV-2: friends or foes? A case report
}

\author{
Elena Garlatti Costa, ${ }^{1}$ Cesare Mazzaro, ${ }^{2}$ Alessandro Grembiale, ${ }^{1}$ Alessandro Berto, ${ }^{3}$ Rita De Rosa, ${ }^{3}$ \\ Silvia Grazioli, ${ }^{1}$ Maurizio Tonizzo ${ }^{1}$
}

${ }^{1}$ Department of Internal Medicine, ASFO, Azienda Sanitaria Friuli Occidentale, Ospedale Santa Maria degli Angeli, Pordenone; ${ }^{2}$ Clinical and Experimental Onco-Hematology Unit, Centro di Riferimento Oncologico (CRO) Aviano, IRCCS, Aviano (PN); ${ }^{3}$ Department of Microbiology and Virology, ASFO, Azienda Sanitaria Friuli Occidentale, Ospedale Santa Maria degli Angeli, Pordenone, Italy

\begin{abstract}
Data about co-infection of severe acute respiratory syndrome-related coronavirus 2 (SARS-CoV-2), HIV, and hepatitis C virus (HCV) are still scarce. We describe a patient hospitalized for sore throat, fatigue, and myalgia with a personal history of HIV and occult HBV infection. His antiretroviral therapy included bictegravir/emtricitabine/tenofovir alafenamide. The nasopharyngeal swab was positive for SARS-CoV-2 and laboratory testing showed acute HCV. Antiretroviral therapy was continued, but no specific therapy for SARS-CoV-2 was started. After 4 weeks, the nasopharyngeal swab resulted negative for SARS-CoV-2 and biochemical tests revealed undetectable HCV RNA with normalization of transaminases. To the best of our knowledge, this is the first reported case of acute HCV in a patient with HIV and SARS-CoV-2 co-infection.
\end{abstract}

\section{Introduction}

Co-infection of severe acute respiratory syndrome-related coronavirus 2 (SARS-CoV-2) and

Correspondence: Cesare Mazzaro, Clinical and Experimental Onco-Hematology Unit, Centro di Riferimento Oncologico (CRO) Aviano, IRCCS, via Franco Gallini 2, 33081 Aviano (PN), Italy.

Tel.: 39.0434.659111.E-mail: cesare.mazzaro@gmail.com

Key words: SARS-CoV-2; HCV; HIV; co-infection; Italy.

Acknowledgments: the authors wish to thank Mrs. Luigina Mei for her editorial assistance.

Contributions: EGC E, CM, and AG conceived the study, provided clinical expertise, and drafted the report; $\mathrm{AB}, \mathrm{RDR}, \mathrm{SG}$, MT provided expertise in the interpretation of clinical implications and critically revised the manuscript. All authors read and approved the final version for submission.

Conflict of interests: the authors declare no potential conflict of interests.

Ethics and consent to participate: the patient provided written informed consent for the use of clinical data for research purposes, in agreement with the Ethical Principles for Medical Research involving Human Subjects and the Declaration of Helsinki.

Received for publication: 30 July 2020.

Accepted for publication: 9 February 2021.

This work is licensed under a Creative Commons Attribution NonCommercial 4.0 License (CC BY-NC 4.0).

${ }^{\circ}$ Copyright: the Author(s), 2021

Licensee PAGEPress, Italy

Italian Journal of Medicine 2021; 15:184-187

doi:10.4081/itjm.2021.1350
HIV is an interesting topic, and data are constantly emerging. Conversely, clinical experiences on hepatitis $\mathrm{C}$ virus (HCV), SARS-CoV-2, and HIV co-infection are still scarce. Zhao et al. ${ }^{1}$ reported the first case of coronavirus disease 2019 (COVID-19) with HIV-1 and chronic HCV, but data on co-infection of SARS-CoV-2, HIV infection, and acute HCV are missing. Considering COVID-19 as a global pandemic, the worldwide burden of HIV, HBV, and $\mathrm{HCV}$ infection, and the worldwide plan to eliminate viral hepatitis, it is essential to improve our knowledge on this topic. Herein, we describe the first case of acute $\mathrm{HCV}$ in a patient with HIV, occult HBV, and SARS-CoV-2 co-infection.

\section{Case Report}

On March 8, 2020, a 25-year-old Nigerian man was admitted to our Department of Internal Medicine because of a sore throat, fatigue, and myalgia over the last 15 days, though without fever or dyspnea. He was unmarried, a student of economics, living in Italy since 2000 . The patient's personal history included HIV infection since 2017 (at the beginning of the disease HIV RNA 42,000 copies/mL and CD4 $358 / \mu \mathrm{L}$ ) and occult HBV infection. A therapy with dolutegravir/abacavir/lamivudine had been prescribed from December 2017 to January 2020, switching to bictegravir/emtricitabine/tenofovir alafenamide because of persistent low viremia, achieving later virological suppression and CD4 cell count equal to $768 / \mu \mathrm{L}$. His adherence to combined antiretroviral therapy was always respected. Screening for HCV and sexually transmitted infections had 
been regularly performed. Liver function tests (LFTs) had always been normal. At hospital admission, the physical examination was negative. Oxygen saturation was $98 \%$, and his arterial blood gas showed $\mathrm{pO}_{2} / \mathrm{FiO}_{2}(21 \%)$ ratio equal to 399 . The nasopharyngeal swab was positive for SARS-CoV-2 real-time reverse transcriptase-polymerase chain reaction (RT-PCR), while dosing of IgM and IgG was not available in our Laboratory at that time.

Routine laboratory testing showed acute hepatitis as follows: alanine aminotransferase (ALT) $924 \mathrm{U} / \mathrm{L}$, aspartate aminotransferase (AST) $497 \mathrm{U} / \mathrm{L}$, total bilirubin $1.4 \mathrm{mg} / \mathrm{dL}$ (direct $0.8 \mathrm{mg} / \mathrm{dL}$ ), $\Upsilon$-glutamyl

Table 1. Patient's laboratory test results.

\begin{tabular}{|c|c|c|}
\hline Parameters & Baseline & $\begin{array}{l}\text { After } \\
4 \text { weeks }\end{array}$ \\
\hline White blood cell count $\left(4.00-11.00 \times 10^{3} / \mu \mathrm{L}\right)$ & 4.14 & 4.50 \\
\hline Lymphocyte $\left(1.00-4.50 \times 10^{3} / \mu \mathrm{L}\right)$ & 2.33 & 2.50 \\
\hline CD4 (493-1666 cell/ $\mu \mathrm{L})$ & 877 & 890 \\
\hline Hemoglobin (12-16 g/dL) & 14.4 & 14.0 \\
\hline Platelets $\left(140-440 \times 10^{3} / \mu / \mathrm{L}\right)$ & 170 & 190 \\
\hline Creatinine $(0.70-1.20 \mathrm{mg} / \mathrm{dL})$ & 0.9 & 0.9 \\
\hline Glycemia $(<100 \mathrm{mg} / \mathrm{dL})$ & 90 & 95 \\
\hline Cholesterol $(<200 \mathrm{mg} / \mathrm{dL})$ & 139 & - \\
\hline Triglycerides $(<150 \mathrm{mg} / \mathrm{dL})$ & 74 & - \\
\hline AST (3-40 U/L) & 497 & 30 \\
\hline ALT (6-78 U/L) & 924 & 41 \\
\hline $\operatorname{ALP}(45-117 \mathrm{U} / \mathrm{L})$ & 95 & 90 \\
\hline GGT $(15-85 \mathrm{U} / \mathrm{L})$ & 502 & 100 \\
\hline Total bilirubin $(0.2-1.2 \mathrm{mg} / \mathrm{dL})$ & 1.4 & 0.8 \\
\hline Direct bilirubin $(0-0.4 \mathrm{mg} / \mathrm{dL})$ & 0.8 & 0.3 \\
\hline Albumin $(3.4-5.0 \mathrm{~g} / \mathrm{dL})$ & 4.0 & - \\
\hline Ammonia $(11-35 \mu \mathrm{mol} / \mathrm{L})$ & 30 & 22 \\
\hline Ferritin $(30-300 \mu \mathrm{g} / \mathrm{L})$ & 230 & - \\
\hline LDH (100-240 U/L) & 150 & - \\
\hline INR $<1.20$ & 1.2 & 0.9 \\
\hline D-dimer $(0-500$ ng/mL) & 200 & - \\
\hline $\mathrm{C}$ reactive protein $(0.0-0.5 .5 \mathrm{mg} / \mathrm{dL})$ & 1.5 & $<0.5$ \\
\hline Procalcitonin $(0.02-0.05 \mathrm{ng} / \mathrm{mL})$ & $<0.01$ & $<0.01$ \\
\hline $\begin{array}{l}\text { TSH (thyroid stimulating hormone) } \\
(0.20-3.75 \mathrm{mIU} / \mathrm{L})\end{array}$ & 1.4 & - \\
\hline HCV-RNA (UI/mL) & 117 & Neg \\
\hline HIV-RNA (copies/mL) & $\mathrm{Neg}$ & Neg \\
\hline SARS-CoV-2 (qualitative) & Pos & Neg \\
\hline
\end{tabular}

ALT, alanine aminotransferase; AST, aspartate aminotransferase; ALP, alkaline phosphatase; GGT, $\Upsilon$-glutamyl transferase. transferase (GGT) $502 \mathrm{U} / \mathrm{L}$, INR 1.2, ammonia 30 $\mu \mathrm{mol} / \mathrm{L}$ (Table 1). Chest X-ray was negative while abdomen ultrasound revealed slight liver steatosis, regular caliber of the portal vein, normal size of the spleen, and no ascites. He denied having used alcohol and illicit drugs or traveled abroad, but an episode of unprotected sex in the previous weeks emerged. We planned an additional biochemical investigation that showed negative HIV RNA, HBVDNA, HEV- RNA, CMV-DNA, EBV-DNA, HHV-8-DNA, anti-herpes simplex virus IgM, and anti-hepatitis A virus IgM, while HCV RNA was detected $(117 \mathrm{U} / \mathrm{L})$. Genotype was not determined because of the very low viral load. Markers of autoimmunity (AMA, ASMA, ANA, ENA, native DNA, LKM, ANCA) were negative; IL28 B rs12979860 genotype was C/C. Bictegravir/emtricitabine/tenofovir alafenamide was continued during the hospital stay, but no specific therapy for SARSCoV-2 was started. After one week, the patient recovered from the symptoms, and he was discharged from the hospital. LFTs were spontaneously improving: ALT $275 \mathrm{U} / \mathrm{L}$, total bilirubin $0.8 \mathrm{mg} / \mathrm{dL}$, and INR 0.9 . After 2 weeks, the second nasopharyngeal swab was persistently positive, while after 4 weeks, the nasopharyngeal swab resulted negative for SARS-CoV2 and serum biochemical tests revealed undetectable HCV RNA (Table 1). Presently, the patient is still closely monitored.

\section{Discussion}

SARS-CoV-2, the causative agent of COVID-19, has been reported in over 15 million individuals worldwide. ${ }^{2}$ Fever, cough, fatigue, and shortness of breath are predominant clinical manifestations, with the disease taking on a severe course in $25 \%$ of subjects. ${ }^{3}$ Clinical picture of SARS-CoV-2 infection in patients with HIV can be heterogeneous, ranging from severe pneumonia to a mild or asymptomatic coronavirus infection disease. ${ }^{4}$ According to some authors ${ }^{5,6}$ in this special population, the determining factors for the clinical course and prognosis are baseline immunovirological status, presence of comorbidities, and probably the type of combined antiretroviral therapy used. Although increasing COVID-19 cases were expected in HIV-infected people, some authors have observed low incidence (1-2\%) and low mortality rates. ${ }^{5,6}$ In particular, the issue of whether anti-HIV drugs are associated with tangible clinical benefits among SARS-CoV-2 infected patients is difficult to disentangle because literature data are discordant. Härter et al. ${ }^{6}$ have not found clear evidence of a protective effect of tenofovir even if the nucleoside ana$\log$ remdesivir, which is currently tested in several 
clinical trials for COVID-19, ${ }^{7}$ has some chemical similarities to tenofovir alafenamide. Similarly, Riva et al. ${ }^{5}$ found that darunavir does not prevent SARSCoV-2 infection in HIV patients.

In our opinion, our case could be interesting in some aspects. Even if the antiretroviral treatment of the patient included tenofovir alafenamide, he experienced a SARS-CoV-2 infection. He reported vague symptoms, no comorbidities, and successfully recovered from minor infection in the absence of therapy. The time for resolution seemed quite long as the nasopharyngeal swab resulted negative for SARS-CoV-2 after 4 weeks. This fact led us to presume that the initial viral load was relatively high, and the acute HCV infection probably had a concomitant role in determining a delayed virus clearance. Indeed, in HIV and SARS-CoV2 co-infection, the median time to viral clearance in individuals admitted to hospitals is 18 days. ${ }^{78}$ Considering the particular immunological situation of HIV infection, a combined diagnosis using a nasopharyngeal swab with serology immunoassays detecting the SARS-CoV-2 immunoglobulin $\mathrm{M}(\operatorname{IgM})$ and immunoglobulin $\mathrm{G}(\mathrm{IgG})$ could appear reasonable. In fact, direct tests based on RT-PCR can show false-negative results because of low viral load in the early phase of the disease, virus mutation, and specimen inadequacy. On the other hand, serology is the best approach because IgM anti SARS-CoV-2 becomes detectable just 7-8 days after onset of symptoms, ${ }^{9}$ but is not routinely used. Furthermore, additional real-life observations are necessary to study the serology of SARS-CoV-2 infection in people living with HIV.

Secondly, our clinical experience resumes the importance of elevated liver biochemistries during COVID-19. The incidence of elevated serum liver biochemistries in hospitalized patients with SARS-CoV2 ranges between $14 \%$ and $53 \%{ }^{10}$ When assessing these patients, it is recommended to consider also etiologies unrelated to SARS-CoV-2, particularly HBV and $\mathrm{HCV},{ }^{11}$ and our case highlights the importance of acute hepatitis C. In fact, acute sexually transmitted $\mathrm{HCV}$ infection continues to be a serious health burden, ${ }^{12}$ and major effective interventions are needed to control this disease.

Concerning virology, similarly to $\mathrm{HCV}$, the SARS$\mathrm{CoV}-2$ genome is characterized by a positive-sense single-strand RNA and shares a similar replication mechanism requiring an RNA-dependent RNA polymerase (RdRp). So, direct antiviral agents as sofosbuvir/velpatasvir used as a standard of care for $\mathrm{HCV}$ infection could be an attractive candidate as SARSCoV-2 specific antiviral agent ${ }^{13}$ while about HIV and SARS-CoV-2, a recent current report has demonstrated that HIV did not contribute to the 2019-nCoV genome. ${ }^{14}$

\section{Conclusions}

Co-infection with HIV, HCV, and SARS-CoV-2 is uncommon. A Chinese case report ${ }^{1}$ described COVID19 in a patient with HIV and chronic HCV co-infection, while according to the latest state of our knowledge, our case reporting acute hepatitis $\mathrm{C}$ in HIV and SARS-CoV-2 infection is the first occurred in Italy. More extensive real-life experiences are needed to explain the virology of these three viral infections together and to confirm the clinical disease, prognosis, diagnosis, and therapy of COVID-19 in this group of patients. In the future, combined serological screening for HIV, HCV, and SARS-CoV-2 could be an essential tool and a first step to determine an early diagnosis with prompt specific therapy, especially for HIV and HCV infections.

\section{References}

1. Zhao J, Liao X, Wang H, et al. Early virus clearance and delayed antibody response in a case of COVID-19 with a history of co-infection with HIV-1 and HCV. Clin Infect Dis 2020 [Epub ahead of print].

2. The Center for Systems Science and Engineering (CSSE) at Johns Hopkins University. Coronavirus COVID-19 global cases. Available from: https://gisanddata.maps.arcgis.com/apps/opsdashboard/index.html\#/b da7594740fd40299423467b48e9ecf6 Accessed: July 28, 2020.

3. Fu L, Wang B, Yuan T, et al. Clinical characteristics of coronavirus disease (COVID-19) in China: a systematic review and meta-analysis. J Infect 2020;80:656-65.

4. Blanco JL, Ambrosini J, Garcia F, et al. COVID-19 in patients with HIV: clinical case series, Lancet HIV 2020;7:e314-6.

5. Riva A, Conti F, Bernacchia D, et al. Darunavir does not prevent SARS-CoV-2 infection in HIV patients. Pharmacol Res 2020;157:104826.

6. Härter G, Spinner CD, Roider J, et al. COVID-19 in people living with human immunodeficiency virus: a case series of 33 patients. Infection 2020 [Epub ahead of print].

7. Elfiky AA. Ribavirin, remdesivir, sofosbuvir, galidesivir, and tenofovir against SARS-CoV.2 RNA dependent RNA polymerase (RdRp): a molecular docking study. Life Sci 2020;25:117592.

8. Vizcarra P, Perez-Elias MJ, Quereda C, et al. Description of COVID-19 in HIV-infected individuals: a single-centre, prospective cohort. Lancet HIV 2020 [Epub ahead of print].

9. Sanduzzi A, Sanduzzi Zamparelli S. Nasopharyngeal and oropharyngeal swabs, and/or serology for SARS COVID-19: what we are looking for? Int J Environ Res Public Health 2020;17:3289.

10. Zhang C, Shi L, Wang F-S. Liver injury in COVID-19: management and challenges. Lancet Gastroenterol Hepatol 2020 [Epub ahead of print].

11. American Association for the Study of Liver Diseases. 
Clinical insights for hepatology and liver transplant providers during the COVID-19 pandemic. Released: April 7, 2020. Available from: www.aasld.org

12. Kamal SM. Acute hepatitis C: a systematic review. Am J Gastroenterol 2008;103:1283-97.

13. Izzi A, Messina A, Rinaldi L, et al. Editorial-Sofosbuvir/velpatasvir as a combination with strong potential activity against SARS-CoV2 (COVID-19) infection: how to use direct-acting antivirals as broad-spectrum antiviral agents. Eur Rev Med Pharmacol Sci 2020;24: 5193-4.

14. Xiao C, Li X, Liu S, et al. HIV-1 did not contribute to the 2019-nCoV genome. Emerg Microb Infect 2020;9: $379-81$. 